\title{
Endoscopic diagnosis of secondary rectal teratoma in a young woman with constipation and positive fecal occult blood test
}

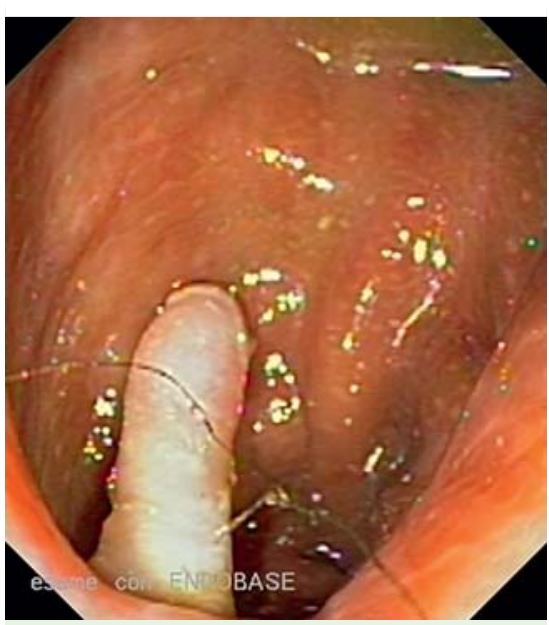

Fig. 1 Finger-like polypoid lesion of about $2 \mathrm{~cm}$ on the anterior wall of the rectum, with hair growth on the surface.
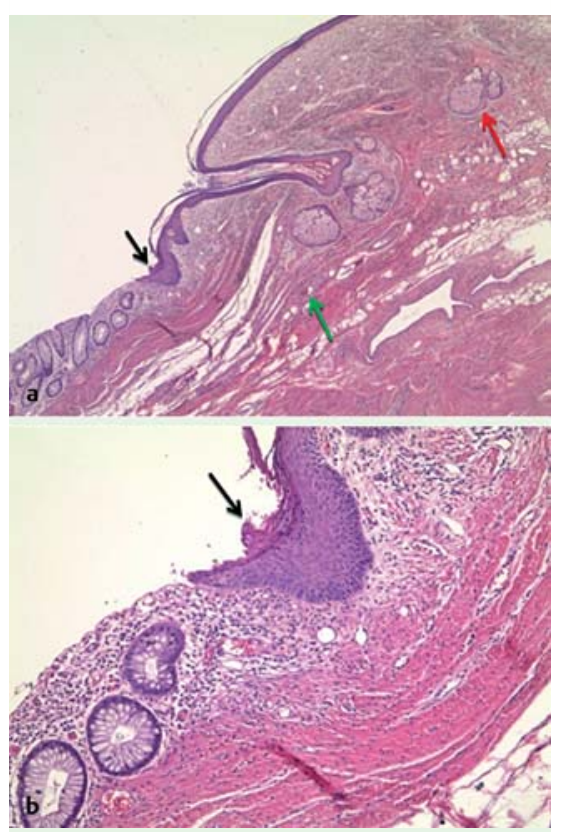

Fig. 3 a, b Benign mature cystic teratoma. The photomicrographs show the colonic mucosa in continuity with the epidermis of the skin, with focal hyperparakeratosis (black arrow). Note the annexal structures (red arrow) and blood vessels (green arrow) in the dermis (hematoxylin and eosin, magnification (a) $\times 106$ and $(\mathbf{b}) \times 200$ ).

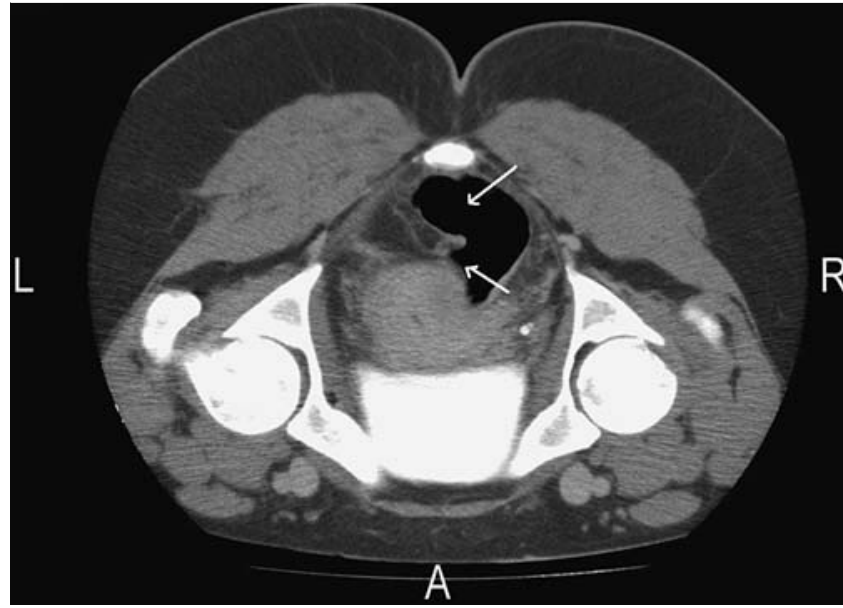

Fig. 2 Computed tomography (CT) scan of the abdomen and pelvis showing a heterogeneous bilateral ovarian mass adhering to the anterior wall of rectum with an intraluminal protruding mass of approximately $2 \mathrm{~cm}$ in length (white arrows).

In the literature there are several reports of primary teratomas of the rectum [1]; however, the incidence of ovarian teratoma with secondary rectal involvement is extremely rare (10 cases in the literature in the past 100 years) [2]. Ovarian teratoma is usually a benign lesion, containing a diversity of tissues including hair, teeth, bone, and thyroid [3]. It is mostly detected in the childbearing years, and up to $15 \%$ of women have bilateral lesions. The prevalence of complications is $<5 \%$, and the complications include torsion, rupture, infection, and malignant transformation $[4,5]$. We present a case of a 31-year-old woman who was referred to our gastrointestinal unit because of constipation, lower abdominal pain, tenesmus, and a positive fecal occult blood test. She also reported having dysmenorrhea in the past 3 months. Blood and biochemistry data showed only a slight increase in alpha ${ }_{1}$ fetoprotein $(13.3 \mathrm{ng} / \mathrm{mL}$, normal values $<6 \mathrm{ng} / \mathrm{mL}$ ). Colonoscopy revealed a finger-like polypoid lesion on the anterior wall of the rectum, at about $15 \mathrm{~cm}$ from anal verge. The lesion was approximately $2 \mathrm{~cm}$ in size, translucent, firm in consistency when held with the biopsy forceps, with hair growth on the surface (๑ Fig. 1).

In addition, pulling on the lesion elicited pain. Histological examination of the endoscopic biopsy specimens from the lesion showed squamous epithelium (data not shown). A computed tomographic (CT) scan of the abdomen and pelvis revealed a bilateral ovarian mass adhering to the anterior wall of rectum, with an intraluminal, protruding mass of approximately $2 \mathrm{~cm}$ ( Fig. 2 ).

The patient was therefore referred to the department of surgery for resection of the ovarian mass along with anterior rectal resection and colorectal anastomosis. Histological examination of the resected colonic segment showed the features of a benign mature cystic teratoma ( $\bullet$ Fig. 3 ). The endoscopic appearance of the lesion in our patient, its translucent nature, and presence of hair on its surface were highly suggestive of a teratoma and the decision was taken not to proceed with endoscopic resection of the polyp. In fact, while endoscopic resection is indicated in primary teratoma of the rectum, secondary lesions must be treated surgically [2]. The evolution of ovarian teratomas is often related to the growth pattern of teratoma. If the growth is rapid, the blood supply to the lesion is compromised, with consequent torsion and rupture. If the growth is slow, inflammation and adhesion to contiguous structures such as the rectum may occur, which eventually lead to protrusion within the intestinal lumen.

\section{Competing interests: None}

Endoscopy_UCTN_Code_CCL_1AD_2AC 
A. Federico ${ }^{1}$, A. G. Gravina ${ }^{1}$, A. Tiso ${ }^{1}$, A. Miranda ${ }^{1}$, F. P. D’Armiento ${ }^{2}$, M. Mascolo ${ }^{2}$, S. Maurea ${ }^{2}$, M. Romano ${ }^{1}$ 1 Division of Hepato-Gastroenterology, Second University of Naples, Naples, Italy

2 Department of Biomorphological and Functional Sciences, University ‘Federico II' of Naples, Naples, Italy

\section{References}

1 Takao Y, Shimamoto C, Hazama K et al. Primary rectal teratoma: EUS features and review of the literature. Gastrointest Endosc 2000; 51: $353-355$

2 Landmann DD, Lewis RW. Benign cystic ovarian teratoma with colorectal involvement: report of a case and review of the literature. Dis Colon Rectum 1988; 31: 808-813

3 Berek JS, Hacker NF. Practical Gynecologic Oncology. 3rd edn. Philadelphia: Lippincott Williams \& Wilkins, 2002: 229

4 Zalatha A, Dubecz S, Harka I et al. Malignant teratoma of the left colon associated with chronic ulcerative colitis. Virchows Arch A 1987; 411: $61-65$

5 Bal A, Mohan H, Singh SB et al. Malignant transformation in mature cystic teratoma of the ovary: report of five cases and review of the literature. Arch Gynecol Obstet 2007; 275: $179-182$

\section{Bibliography}

DOI $10.1055 / \mathrm{s}-0030-1255645$

Endoscopy 2010; 42: E254-E255

(c) Georg Thieme Verlag KG Stuttgart · New York . ISSN 0013-726X

\section{Corresponding author}

\section{A. Federico, MD, PhD}

Division of Hepato-Gastroenterology

Second University of Naples

Via Pansini 5

80131 Naples

Italy

Fax: +390-815666714

alessandro.federico@unina2.it 